\title{
9 Environmental quality for everyone? Socio-structural inequalities in mobility, access to green spaces and air quality
}

\section{Michael Friesenecker, Bernhard Riederer and Roberta Cucca}

\section{Introduction}

In the mid-1990s, urban planning approaches entered an era where sustainability goals, alongside the goal of climate protection, increasingly became woven into urban policy and planning (Wheeler, 2013). Initially conceptualised as a means of balancing environmental protection, social equality and economic growth, the sustainability concept was increasingly used by policymakers to emphasise, predominantly, the (smart) economic growth agenda (While et al., 2004). Whilst sustainability remains an important umbrella concept, more recently it has dovetailed with other concepts, such as the 'smart city', the 'resilient city' and the 'low-carbon city', to name a few (see de Jong et al., 2015). Beginning in 2010, the smart city concept became the new driving force for sustainable development. According to de Jong et al. (2015), the promotion of social inclusion and economic growth through digitalisation became distinctive features. More recently, the resilient city concept has emerged, with a focus on dampening the effects of climate change and other crises through adaption or introduction of green, grey and blue (water-related) urban infrastructure at finer spatial and temporal scales (Connolly, 2019).

Nevertheless, these policies have been met with severe criticism. There is evidence that greening strategies, intended or otherwise, might trigger the (re-)production of socio-spatial inequalities in access to environmental resources (Cucca, 2020). Connolly (2019), for instance, argues that the contemporary planning orthodoxy of the 'Smart Sustainable Resilient City' produces higher levels of social inequalities because planning policies often disregard questions of social equity. From this perspective, environmental improvements tend to 
favour the already well-off, leading to gentrification, poverty and the displacement of the most vulnerable. Nevertheless, it very much depends on the context, especially with regard to differences between North America and Europe. Whilst the strong emphasis on public policies geared towards environmental improvements and enhancing the quality of life in European cities may deepen socio-spatial inequalities, these policies may also contain inequalities. In particular, Vienna has been praised for developing local housing policies that limit the rise of socio-spatial inequalities driven by urban greening and other environmental strategies (Anguelovski et al., 2018; Cucca, 2019).

Vienna's planning approach, which has traditionally focused on social equity and environmental protection, turned towards sustainability in the late 1990s, and this was further developed into a Smart City Strategy in 2014. With sustainability, economic development became equally as important as ecological and social concerns. Yet, Vienna pursued the delivery of its social and health-oriented key services to ensure healthy, liveable environments. Therefore, Vienna's status as a green city, characterised by high quality of life and excellent environmental quality, has not suffered. As such, Vienna has ranked amongst the highest performing European cities in relation to resident satisfaction with air quality, public transport, cleanliness and green spaces (Verwiebe et al., 2020, pp. 21-34).

Against this background, we examine Vienna's status as a liveable and green city more closely, with a particular emphasis on weighing up how 'just' it is. In doing so, we focus on different social groups' perceptions of environmental quality. Hence, our analysis seeks to answer the research questions: what is the extent of disparities in perceived environmental quality across social groups and how have these inequalities developed over time? Discussing the relationship between our findings and Vienna's environmental approach, we aim to explore possible social trade-offs and limitations of environmentally oriented policies.

In doing so, we draw on the concepts of recognitional and distributional justice, which have been central to the study of environmental justice (Schlosberg, 2007). The (lack of) recognition of group differences is conceptualised as an 'institutional practice' that may (re-) produce unequal distributional outcomes (ibid., p. 16; following the work of Nancy Fraser). In order to identify group differences, we use perceived environmental quality data for different social groups and housing areas to approximate distributional effects. We focus on the perception of space, measured through the satisfaction with environmental qualities, because it conditions people's use of space 
and forms an important part of their daily lived realities (Merrifield, 1993, p. 524). However, as spatial-environmental policies have limited capabilities to improve the socio-economic conditions of individuals (Mouratidis, 2020), environmental policies should be understood as being complementary to a range of other policies, such as housing, welfare and labour market policies.

This chapter will proceed as follows: after outlining our analytical approach, we provide some context by describing Vienna's environmentally oriented policies, followed by a quantitative analysis of changes in perceived environmental quality of different social groups over time. In the concluding section, we will discuss the relation between (a) changes in environmentally oriented policies and (b) changes in perceived environmental quality in Vienna.

\section{An analysis of Vienna's urban environmental justice}

Our analytical approach was comprised of several steps: first, a qualitative analysis of policy documents and grey literature with the aim of identifying the most important reforms and instruments of Vienna's environmental policy approach since 1990. The documents and literature were thematically coded with a focus on social equity, especially if and how social disparities have been addressed through specific environmental improvements targeted at different social groups or housing areas.

Second, we analysed the distributional outcomes in terms of perceived environmental quality over time, employing data from the Viennese Quality of Life Survey for the years 2003, 2008, 2013 and 2018. ${ }^{1}$ We constructed a perceived environmental quality index using information from five items within the questionnaire. Respondents evaluated (1) air quality, (2) road cleaning and (3) waste disposal in their living environment on a five-point scale $(1=$ no problems, $5=$ large problems). Furthermore, they reported their opinion on whether improvements are needed regarding the availability of (4) public transport and (5) green spaces, including courtyard greening (2003-2013: yes/no; 2018: five-point rating scale with 1 indicating highest relevance). The index counts the number of problems (values 3 to 5 on the first three items) and needs (yes answers 2003-2013, value 1 in 2018) regarding the living environment. It ranges from 0 (highest perceived quality) to 5 (lowest perceived quality).

Following a description of the changes in environmental quality, we ran a series of binary logistic regression models for 2003 and 2018 (no problems/needs vs. at least one). In these models, we examine the 
differences in perceived environmental quality across the dimensions of (a) labour market position, (b) equivalised net household income including welfare transfers (quantiles), (c) age groups, (d) gender (bivariate associations), (e) migration (country of birth in categories) and (f) housing areas (by the dominant type and age of buildings). The method proposed by Allison (1999) and Hoetker (2007) is applied to test whether the coefficients differ between the separately estimated models for 2003 and 2018, thus indicating changes in differences between social groups over time. Additionally, applying the KHB method (Karlson et al., 2012), we compared the group differences observed in the bivariate models for 2018 with the group differences in a multiple regression model for 2018 containing all variables (a)-(f) simultaneously. If a group difference is smaller in the multiple regression model than in the respective bivariate model, other variables account for it (indicating explanations for the initial group difference observed in the bivariate model). All main text tables show average marginal effects that were derived from the estimated regression models, which enhance the comparability of results stemming from different logistic models.

\section{Vienna's environmental policy approach}

Vienna stands out when it comes to key criteria for evaluating environmental justice. That is, according to a recent comparative investigation examining the urban greening policy trajectories of 50 cities in Europe, Canada and the United States over the last 25 years, its focus on health and equitable access to green infrastructures (Anguelovski et al., 2018). Aiming at social equity and a decent quality of life for all residents, the prime focus in Vienna has traditionally been on health, education and social welfare policies, including housing. This focus continues to be reflected in the budget plan of 2021: expenditures for social welfare and housing subsidies account for around $20 \%$ of the overall expenses, followed by $19 \%$ for both education and health. ${ }^{2}$ Within this social and health-oriented focus, Vienna's environmental approach developed during the 1970s, when the newly founded Department of Environmental Protection and the Department of Urban Planning mainstreamed environmental concerns (Mocca et al., 2020). As a social-ecological approach to urban development, it centred around the notion of a 'healthy, liveable environment' contributing to, and improving the quality of life for Vienna's residents (Pirhofer and Stimmer, 2007, pp. 74-76). Services provided by the City - mainly public transport, green space, high-quality water supply, waste and 
resource management - are framed as socio-ecological key services which provide healthy environments whilst limiting environmental impacts at the same time.

During the 1990s, under the influence of international and EU environmental policies, Vienna's urban policy developed a stronger environmental orientation, with an emphasis on climate protection and the reduction of emissions. At the same time, sustainability came to be the leading principle in urban planning. Within the sustainability framework, economic development emerged as an important cornerstone in planning, equal to ecological and social concerns (see Chapter by 8 by Brenner et al. in this volume). This shift was made possible by decentralisation of the City's competences in regional economic and labour market policies, which were limited up until the 1990s (see Chapter 6 by Ahn and Kazepov in this volume). And it was justified by the City in light of Vienna's exposure to the inter-urban competition through Austria's accession to the EU. Facing the enlargement of the EU in 2004, the City saw the potential to position Vienna as a regional economic centre. Therefore, in the 2000s, Vienna started to market its social and ecological location qualities and services more prominently in order to strengthen Vienna's position as an important international business and research location (see Mocca et al., 2020, pp. 9-10).

Despite this shift towards branding and economic development, Vienna kept its commitment to its social and health-oriented key values and services. Waste management, water supply and road cleaning were never privatised and remained part of the administration, thus maintaining stable fees and high-quality services. Although energy provision and public transport were privatised in 1999 (Plank, 2020), the City retained full ownership of its transport operator and energy provider. As such, Vienna preserved the possibility of further shaping its socio-ecological approach. For example, the heating of social housing premises relies to a large degree on the use of cogeneration and waste incineration plants, which are equipped with a filtering technique to lower air pollution and greenhouse gases. Furthermore, existing social housing was retrofitted as a means of reducing emissions (Mocca et al., 2020).

Public transport represents another major social-ecological service in Vienna, as reflected in very high satisfaction scores (96\%) compared to other European cities, such as London (88\%), Stockholm (81\%), Brussels (75\%) or Lisbon (60\%) (Verwiebe et al., 2020, p. 21). The local transport operator (Wiener Linien) remains heavily subsidised, enabling it to expand its network and improve its service by shortening headways and expanding the hours of service. Despite its privatisation 
in 1999, Wiener Linien has consistently received around 5\% of the city's total expenditures per annum as subsidies, ${ }^{2}$ cross-financed in part by revenue from parking space management (Buehler et al., 2016, p. 264). Most important for social equity and recognition was the introduction of a reduced fee for annual tickets. Campaigned as a $100 €$ ticket by the Green Party in the 2010 election, a $365 €$ ticket was finally introduced in coalition with the Social Democrats in 2012 (see Buehler et al., 2016 for details). Furthermore, the city's public transport approach also recognises the specific needs of some segments of the population, including the elderly, students and the socially excluded.

Yet, transport remains critical with regard to social and spatial disparities in environmental quality. The introduction of a new parking management system in 1993 (see again Buehler et al., 2016), accompanied by interventions in winter road clearance and the decrease of emission intensive fuel for heating in the beginning of the 2000s, led to a reduction in air pollution across most of the city (Kurz et al., 2014). Although car use for commuting to work fell from 38\% in 2003 to $24 \%$ in 2018 (Verwiebe et al., 2020, p. 203), socio-spatial inequalities still exist between central and outer districts in terms of car-ownership, mobility behaviour and access to public transport (Haslauer et al., 2015; Bärnthaler et al., 2020). Furthermore, models by Kurz et al. (2014) clearly show that highways and main roads remain the main source of air pollution.

Finally, the preservation of green space is framed as another key feature contributing to quality of life for Vienna's residents. Around $50 \%$ of the city area is green space, though historic urbanisation patterns have led to uneven distribution and availability of green spaces (Haslauer et al., 2015). Satisfaction is high compared to other European cities, with $93 \%$ of the Viennese population reporting satisfaction with the provision of green space, compared to Barcelona $(68 \%)$ and Amsterdam (89\%) (Verwiebe et al., 2020). Influenced by increasing re-urbanisation of the inner-city district, the administration recognised an increasing need for the development and extension of green space during the 2000s. Furthermore, the experience of pronounced heatwaves led to a growing awareness of social disparities in the local provision of green and blue infrastructure, and their heightened effects on some members of the population, including the elderly, socially excluded and low-income residents (see Chapter 8 by Brenner et al. in this volume for more details).

Shifting to a Smart City Strategy in 2014, Vienna's focus on sustainability and enhancing quality of life through the provision of key services remained the underlying principles in its environmental policy 
and urban planning. Although Vienna's environmental and social focus contrasts with stronger business and technology orientated smart city concepts, such as those of Barcelona or Berlin, innovation and technologies have become more important in linking economic development and environmental protection (Exner et al., 2018). Apart from responding to EU-related funding opportunities and branding Vienna as a business location, a major aim of the Smart City Strategy is to foster inter-departmental cooperation in climate protection policy (ibid.).

\section{Socio-structural inequalities and perceived environmental quality}

The above discussion has outlined Vienna's environmental approach and its main policy instruments, but also highlighted some criticisms in terms of uneven distribution of green space, air pollution and availability of public transport. In this section, we analyse perceived improvements in environmental quality and disparities between social groups. In so doing, we aim to grasp disparities in the lived experiences of different groups in relation to environmental qualities. This focus emphasises the importance of human-nature relations rather than solely focusing on improvements of the built environment. We first do this by considering the overall trends, and second by considering socio-demographic and spatial differences.

Overall, the perceived environmental quality in Vienna is high and has improved over time (see Figure 9.1): in 2018, 44\% of the Viennese reported they did not have a single problem or need in relation to their living environment ( $72 \%$ reported at most one problem), compared to $36 \%$ in 2003 (68\% reported at most one problem). Trends over time for single indicators of environmental quality are mixed. A need for green space, problems with air quality and problems with road cleaning were less often reported in 2018 compared to 15 years previous. Nevertheless, the need for additional green space remains the main concern of the Viennese (31\% in 2003 and $26 \%$ in 2018). Problems with waste disposal were rarely reported and figures remained stable $(\sim 10 \%)$. In the growing city, however, only $18 \%$ reported the need for improved access to public transport in 2003 compared to $25 \%$ in 2018 . Thus, reforms regarding the regulation of car traffic, for instance, seemed to be successful at meeting the perceived needs of residents whereas the population growth and development of new housing areas raised additional needs for a further expansion of public transport.

Whilst these findings are positive in general, there are pronounced differences in perceived environmental quality between social groups 


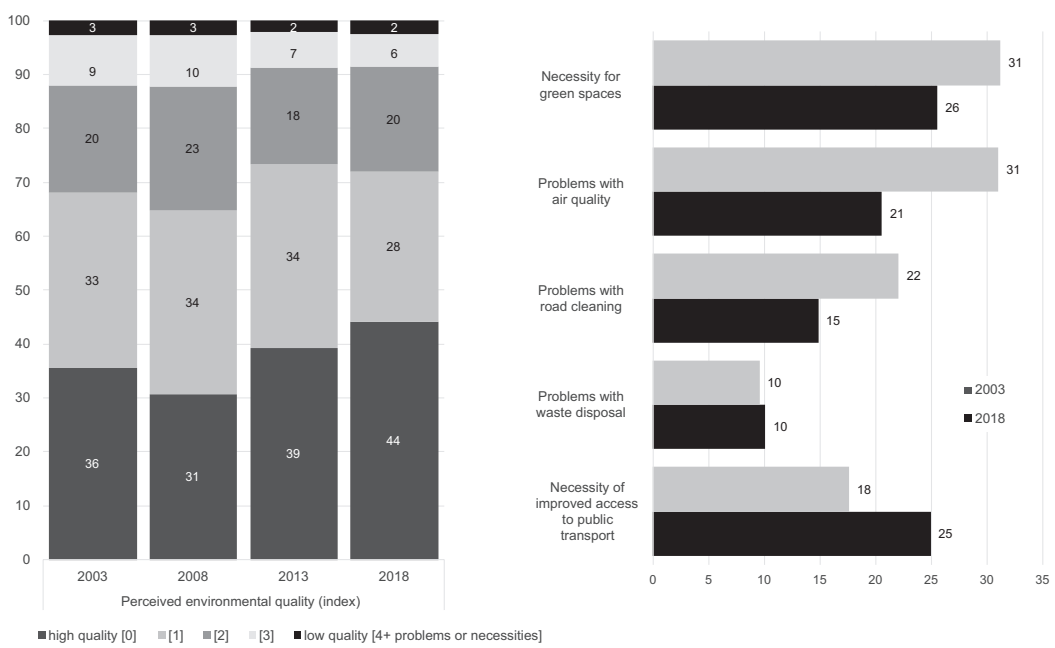

Figure 9.1 Perceived quality of the living environment in Vienna (in \%). Source: Viennese Quality of Life Survey 2003 to 2018; own weighted computation.

Note: Perceived environmental quality $(0-5)$ is measured by counting reported problems with air quality, road cleaning and waste disposal and necessities of improvements in public transport and of additional green space.

(see Table 9.1). Perceived environmental quality differs by labour market position, household income, age, gender and country of birth. Whereas certain differences have remained constant (e.g. those relating to country of birth), some even increased between 2003 and 2018 (i.e. those by labour market position), leading to further social polarisation in perceived environmental quality, which supports the scepticism of some authors (Connolly, 2019; Cucca, 2020). Labour market position did not have much influence on the evaluation of the living environment in 2003. However, it has become highly relevant in 2018, when unskilled workers in particular, but also skilled workers, the unemployed and students showed lower probabilities of living in high-quality environments (see Table 9.1, 3rd column). Most of these differences are diminishing if other variables are included (see Table 9.1, 4th column), suggesting that effects of labour market position on the probability of living in high-quality environments partly result from differences in income and housing areas. Unsurprisingly, people with a lower household income have a lower probability of living in high-quality environments (see Table 9.1). Differences between income groups may be even more pronounced nowadays than in the past. ${ }^{3}$ 
Although there has been some change within groups, overall differences by age, gender and country of birth remained largely constant over time. According to Table 9.1, the share of those living in highquality environments is more than 20 percentage points lower amongst the youngest (below age 30) than amongst the oldest age group (60+) in both 2003 and 2018. In line with this result, retired people report fewer problems or needs in relation to their living environment. These differences by age are partly explained by their labour market position, household income or housing area (compare third and fourth column in Table 9.1). An important aspect relates to restricted access to affordable housing for young newcomers to the city (see Kadi, 2015). In addition, women seem to be slightly underrepresented in high-quality living environments (differences of $2-3$ percentage points), indicating that women who live alone have more difficulties in finding good housing (see Klinenberg, 2012). Finally, there is a pronounced difference between the European-born and the non-European-born population (Table 9.1). In the course of the last decades, the heterogeneity of the increasing immigration to Vienna affected social polarisation, with highly qualified immigrants from EU 15 member countries who have immediate access to the labour market and low-skilled immigrants from third countries as well as asylum seekers and refugees who suffer from legal obstacles (see Riederer et al., 2019, 2020). In 2018, immigrants from Turkey and other non-European countries were characterised as having lower probabilities of living in high-quality environments. ${ }^{4}$ Differences in labour market position, household income and housing area account for a large part of their disadvantaged position (Table 9.1, 4th column). Presumably, weaker economic integration leads to lower income and non-affordability of high-quality living environments, but also discrimination and a lack of access to housing in high-quality environments for socio-economically weak newcomers, cause systematic disadvantages (see Kadi, 2015; Kohlbacher and Reeger, 2020).

Finally, findings on differences in housing areas ${ }^{5}$ also mirror the general picture. The results reflect a general improvement of perceived quality of living environments, but also demonstrate differences between areas. People living in the city centre and surrounding neighbourhoods with buildings built in the period from 1840 to 1918 more frequently report problems than residents of other housing areas, in particular compared to those living in single-family homes (most of them at peripheral locations). Table 9.1 shows, for instance, that in 2003 the share reporting high environmental quality was about 21 percentage points higher amongst those living in single-family homes 


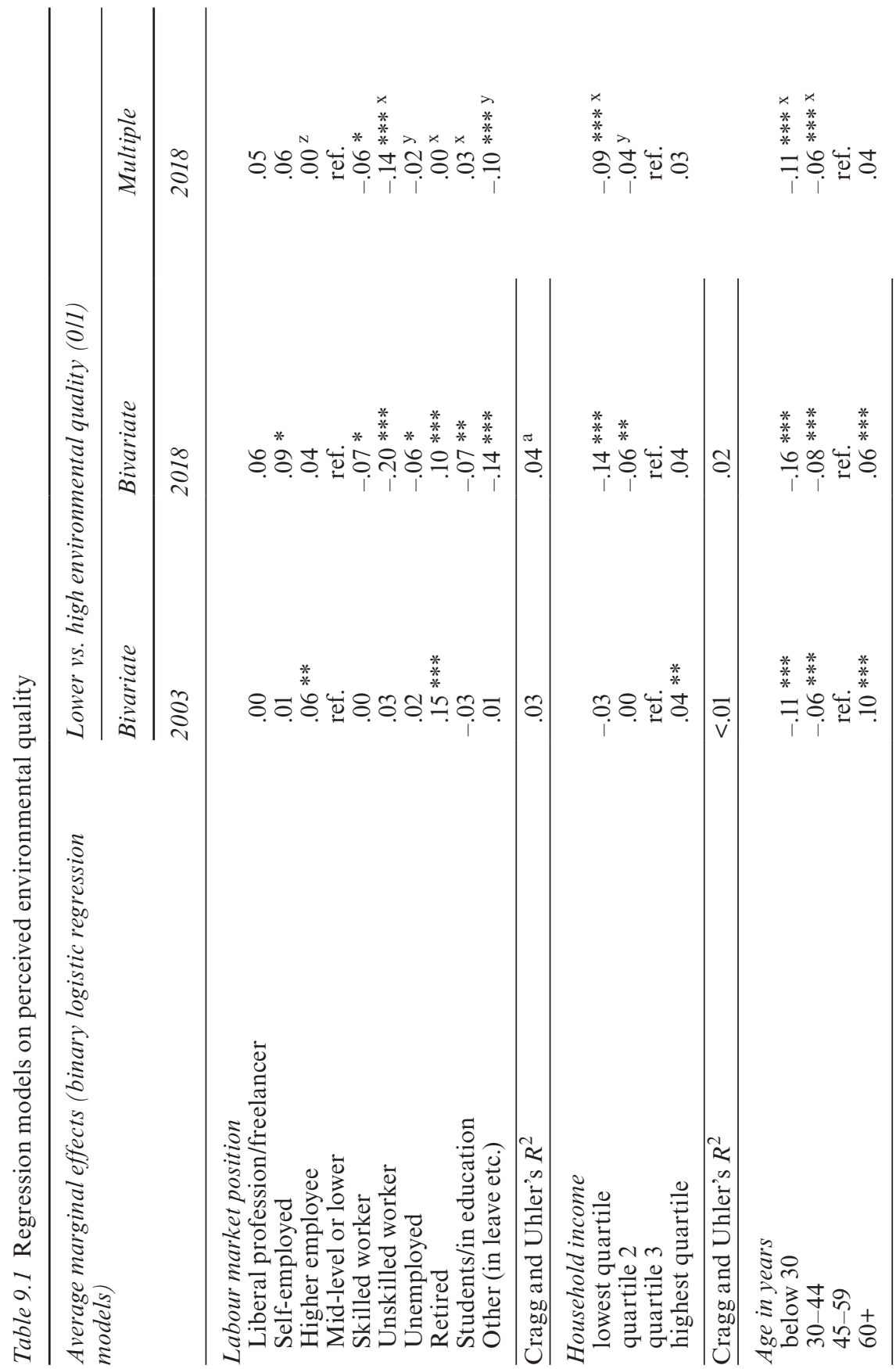




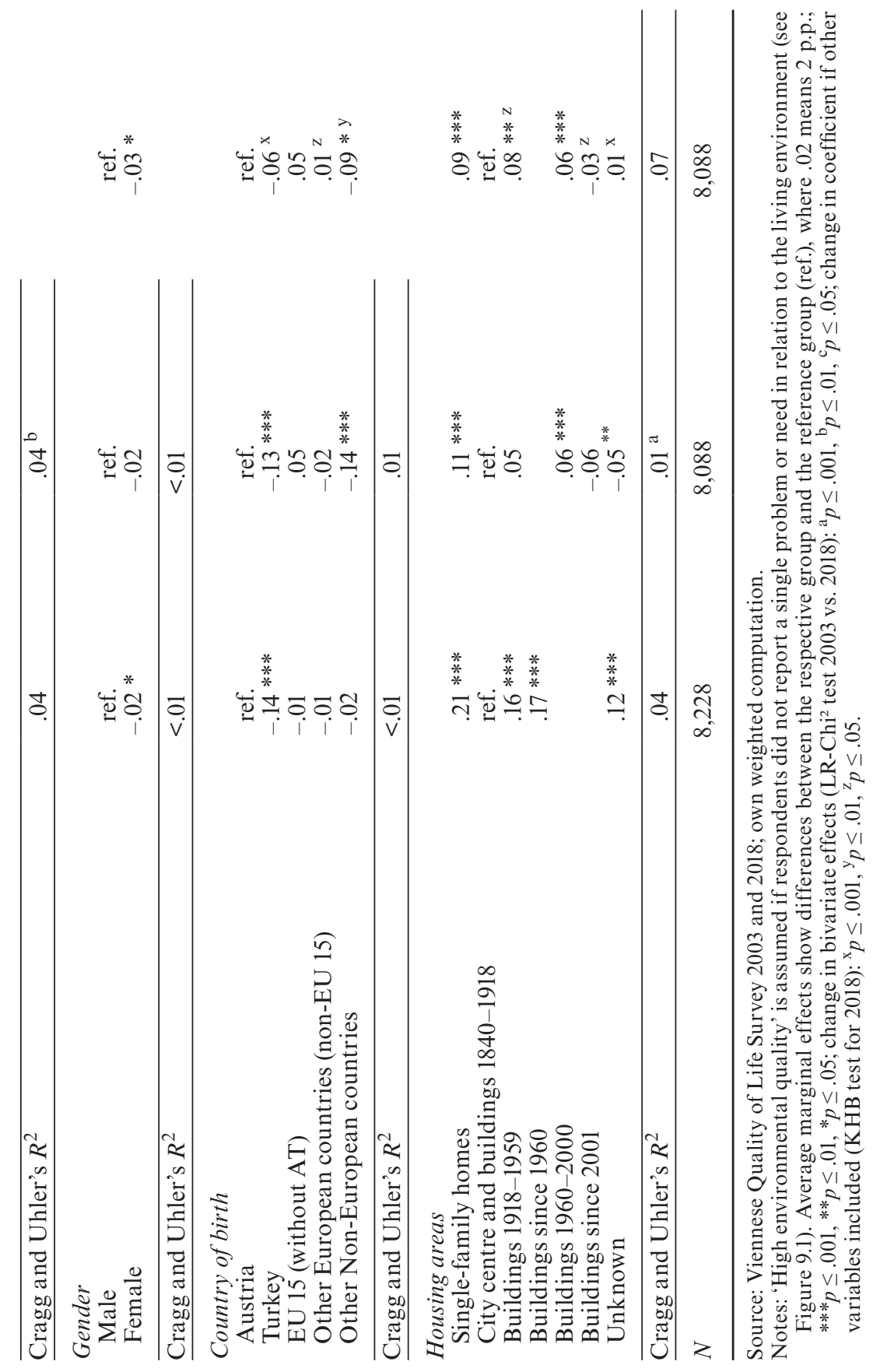


than inner-city residents. Between 2003 and 2018, differences between housing areas have become smaller. This might be related to different lifestyles in the course of social upgrading (Hatz et al., 2016) but is most likely due to efforts in greening and traffic regulation: In 2003, $48 \%$ of inner-city residents reported a need for (additional) green space compared to $29 \%$ in 2018. Similar trends can be observed regarding problems with air quality (41 vs. $26 \%$ ) and road cleaning ( 29 vs. $16 \%$ ). At the periphery, problems are of a different nature: in 2018, 29\% of those living in single-family homes expressed a need for improvements of public transport (2003: $34 \%$ ). The latter is also an issue for $33 \%$ of the residents of new or renewed housing areas (data for 2018 only). In general, it seems that, due to declining differences between housing areas, neighbourhood effects are less important for Vienna than in the past.

\section{Conclusions}

In this chapter, we have analysed how the perception of Vienna's status as a green city has varied over time and across social groups. Furthermore, we aimed to explore how these changes relate to the shifting orientation of Vienna's social-environmental policies in order to discuss possible trade-offs and limitations of environmentally oriented policies.

In comparison to other European cities, the Viennese population is generally very satisfied with the city's environmental qualities. Furthermore, the perceived environmental quality has generally improved from what was already a high level, yet results show that pronounced inequalities exist. Whilst some of the differences remained stable over time, inequalities regarding the labour market position became more profound. Unskilled workers in particular perceive increased deficiencies in the quality of their environments. This seems to intersect with an ethnic dimension, as residents born in Turkey and other non-European countries face barriers on Vienna's labour and housing market. Nevertheless, inequalities between housing areas have fallen and in general the perceived environmental quality has improved but, unsurprisingly, problems with green space, air quality and public transport provision differ between inner-city housing and peripheral districts.

Along with the introduction of sustainability and the smart city concept, Vienna's focus on key services to provide healthy, liveable environments, whilst limiting environmental impacts continued on the whole. This commitment to providing key services mirrors a general improvement in the perceived environmental quality, although 
the sustainable/smart approach was not able to iron out social disparities. With the addition of the economic growth agenda, mostly through locational branding and fostering environmental technologies, our evidence suggests that too little emphasis has been placed on addressing social inequalities in the provision of key services with environmental impacts.

Urban greening is less related to gentrification and displacement in Vienna in comparison to other contexts, and the existence of a good policy mix regarding affordability of housing largely limited inequalities. Nevertheless, when it comes to the lived experience of specific groups, the current situation of environmental justice should be taken seriously. The poorer provision of environmental quality to unskilled workers and the limited improvements for low-income residents in general may endanger the status of Vienna as a 'just' green city. Recent immigration and the associated barriers on the labour and housing markets for newcomers bring about challenges in providing environmental quality to everyone. The recent emergence of the resilience approach might strengthen the recognition of vulnerable groups, which has been so far limited in Vienna's environmental approach. However, it will succeed only if a good level of integration amongst different policy domains can be achieved.

\section{Notes}

1 The data is representative for the population of Vienna (age 15 and above) and includes information from 8,300 to 8,700 respondents each year. Interviews were conducted in German and in the mother tongue of the largest immigrant groups (i.e. those from Turkey and former Yugoslavia). Modes of data collection comprised computer assisted telephone interviews (all waves), face-to-face interviews (300 foreign language interviews, both in 2003 and 2008) and computer assisted web interviews (23\% in 2018). Surveys were conducted by IFES (www.ifes.at) who weighted the data in consideration of design and mode effects.

2 The share of expenses remained stable according to the City's statement of accounts since 1998 (Source: https://bit.ly/3rEOb3h, Accessed 28 March 2021)

3 In $2003,33 \%$ of the lowest and $40 \%$ of the highest income quantile reported no problems or needs concerning their living environment compared to $35 \%$ and $53 \%$ in 2018. However, differences between income groups in 2003 do not significantly differ from differences between income groups in 2018 (LR-Chi ${ }^{2}$ test 2003 vs. 2018; Table 9.1).

4 In 2003, 23\% of Turkish immigrants but $34 \%$ of EU 15 immigrants reported no problems or needs in relation to their living environment. In 2018 , these figures refer to $32 \%$ and $50 \%$, respectively.

5 The classification on housing areas is based on construction period and quality of the housing stock. See Riederer et al. (2019, p.4) for details. 


\section{References}

Allison, P.D., 1999. Comparing logit and probit coefficients across groups. Sociological Methods \& Research, 28(2), pp. 186-208.

Anguelovski, I., Argüelles, L., Baró, F., Cole, H., Connolly, J., García Lamarca, M., Loveless, S., Pulgar, C., Shokry, G., Trebic, T. and Wood, E., 2018. Green trajectories: Municipal policy trends and strategies for greening in Europe, Canada and United States (1999-2016). Available at: https://bit. ly/3sIobVK [Accessed 31 March 2021]

Bärnthaler, R., Novy, A. and Stadelmann, B., 2020. A Polanyi-inspired perspective on social-ecological transformations of cities, Journal of Urban Affairs, pp. 1-25. https://doi.org/10.1080/07352166.2020.1834404.

Buehler, R., Pucher, J. and Altshuler, A., 2017. Vienna's path to sustainable transport, International Journal of Sustainable Transportation, 11(4), pp. 257-271.

Connolly, J.J., 2019. From Jacobs to the Just City: A foundation for challenging the green planning orthodoxy. Cities 91, pp. 64-70.

Cucca, R., 2019. Taking contextual differences into account in green gentrification research. The case of Vienna. Sociologia urbana e rurale, 119, pp. 46-62.

Cucca, R., 2020. Spatial segregation and the quality of the local environment in contemporary cities. In: Musterd, S., ed., 2020. Handbook of urban segregation. Cheltenham: Edward Elgar Publishing. pp. 185-199.

de Jong, M., Joss, S., Schraven, D., Zhan, C. and Weijnen, M., 2015. Sustainable-smart-resilient-low carbon-eco-knowledge cities: Making sense of a multitude of concepts promoting sustainable urbanization. Journal of Cleaner Production, 109, pp. 25-38.

Exner, A., Cepoiu, L., Weinzierl, C. and Asara, V., 2018. Performing smartness differently-strategic enactments of a global imaginary in three European cities. SRE-Discussion Papers 2018/05. WU Vienna University of Economics and Business, Vienna. Available at: https://bit.ly/39uGBSC [Accessed 31 March 2021]

Haslauer, E., Delmelle, E.C., Keul, A., Blaschke, T. and Prinz, T., 2015. Comparing subjective and objective quality of life criteria: A case study of green space and public transport in Vienna, Austria. Social Indicators Research, 124(3), pp. 911-927.

Hatz, G., Kohlbacher, J. and Reeger, U., 2016. Socio-economic segregation in Vienna: A social-oriented approach to urban planning and housing. In: Tammaru, T., Marcinczak, S., van Ham, M. and Musterd, S., eds., 2016. Socio-economic segregation in European capital cities: East meets west. London: Routledge, pp. 80-109.

Hoetker, G., 2007. The use of logit and probit models in strategic management research: Critical issues. Strategic Management Journal, 28(4), pp. 331-343. Kadi, J., 2015. Recommodifying housing in formerly "Red" Vienna? Housing, Theory and Society, 32(3), pp. 247-65.

Karlson, K.B., Holm, A. and Breen, R., 2012. Comparing regression coefficients between same-sample nested models using logit and probit: A new method. Sociological Methodology, 42(1), pp. 286-313. 
Klinenberg, E., 2012. Going solo. The extraordinary rise and surprising appeal of living alone. New York: The Penguin Press.

Kohlbacher, J. and Reeger, U., 2020. Globalization, immigration and ethnic diversity: The exceptional case of Vienna. In: Musterd, S., ed., 2020. Handbook of urban segregation. Cheltenham: Edward Elgar Publishing, pp. 101-117.

Kurz, C., Orthofer, R., Sturm, P., Kaiser, A., Uhrner, U., Reifeltshammer, R. and Rexeis, M, 2014. Projection of the air quality in Vienna between 2005 and 2020 for $\mathrm{NO}_{2}$ and PM10. Urban Climate, 10, pp. 703-719.

Merrifield, A., 1993. Place and space: A Lefebvrian reconciliation. TransactionsInstitute of British Geographers, 18(4), pp. 516-531.

Mocca, E., Friesenecker, M. and Kazepov, Y., 2020. Greening Vienna. The multi-level interplay of urban environmental policy-making. Sustainability, 12(4), pp. 1-18. https://doi.org/10.3390/su12041577.

Mouratidis, K., 2020. Neighborhood characteristics, neighborhood satisfaction, and well-being: The links with neighborhood deprivation. Land Use Policy, 99, pp. 1-12. https://doi.org/10.1016/j.landusepol.2020.104886

Pirhofer, G. and Stimmer, K., 2007. Pläne für Wien. Theorie und Praxis der Wiener Stadtplanung von 1945 bis 2005. Vienna: Municipal Department 18, City of Vienna.

Plank, L., 2019. Öffentliche Dienste weiter denken: Internationale Erfahrungen für Wien. In: Plank, L., Hamedinger, A. and Novy, A., eds., 2019. Wien - Ein Modell im Zukunftstest. Wien: Kurswechsel, pp. 45-52.

Riederer, B., Buber-Ennser, I. and Haindorfer, R., 2020. Trends in demography and migration in Austria. In: Tálas, P. and Etl, A., eds., 2020. Demography and migration in Central and Eastern Europe. Budapest: Dialog Campus Publishing, pp. 9-27.

Riederer, B., Verwiebe, R. and Seewann, L., 2019. On changing social stratification in Vienna: Why are migrants declining from the middle of society? Population, Space and Place, 25(2), pp. 1-11. https://doi.org/10.1002/psp.2215

Schlosberg, D., 2007. Defining environmental justice: Theories, movements, and nature. Oxford: Oxford University Press.

Verwiebe, R., Haindorfer, R., Dorner, J., Liedl, B. and Riederer, B., 2020. Lebensqualität in einer wachsenden Stadt: Wiener Lebensqualitätsstudie 2018. Werkstattbericht 187. Vienna: Stadt Wien, Stadtentwicklung und Stadtplanung.

Wheeler, S.M., 2013. Planning for sustainability: Creating livable, equitable and ecological communities. London: Routledge.

While, A., Jonas, A.E. and Gibbs, D., 2004. The environment and the entrepreneurial city: searching for the urban 'sustainability fix' in Manchester and Leeds. International Journal of Urban and Regional Research, 28(3), pp. 549-569. 